\title{
A Primeira Formação do Conjunto de Folclore Internacional Os Gaúchos
}

\section{Christiane Garcia Macedo ${ }^{1}$ Silvana Vilodire Goellner ${ }^{2}$}

\section{Resumo:}

Este artigo tem como objetivo apresentar um recorte sobre a formação do Conjunto de Folclore Internacional Os Gaúchos, mais especificamente a sua primeira configuração. A história cultural e a história oral foram o referencial teórico-metodológico utilizado. Coletaram-se depoimentos com integrantes do conjunto e documentos. O grupo foi criado em 1959, na cidade de Porto Alegre, e atua com dança folclórica de projeção. Alguns fatores do contexto cultural de Porto Alegre, a partir dos dados levantados, foram fundamentais para o surgimento de um grupo dessa natureza, especialmente: a forte presença na cidade dos Centros de Tradições Gaúchas e das escolas de dança; a realização da Mesa Pan-Americana Feminina; a inauguração da emissora de televisão local; e a aceitação e disponibilidade de pessoas para integrar o conjunto.

Plavras-chave: Dança folclórica; história; Conjunto de Folclore Internacional Os Gaúchos.

\begin{abstract}
:
The article has the objective to present a frame about the formation of the International Folklore Group Os Gauchos, more specifically its first configuration. Cultural history and oral history were the theoretical and methodological framework used. We collected testimonies with group members and documents. The group was created in 1959, in the city of Porto Alegre, and works with projection folk dance. Some factors of Porto Alegre's cultural context, trough obtained data, were crucial for the emergence of such a group, especially: the strong presence in the city of Gaucho Traditions Centers and dance schools; the event of the Pan American Women's Bureau; the inauguration of the local television station; and the acceptance and availability of people to join the group.
\end{abstract}

Key-words: Folk dance; history; International Folklore Group Os Gauchos

1 Doutoranda no Programa de Pós-Graduação em Ciências do Movimento Humano. E-mail: chrisgmacedo@ gmail.com

2 Professora Associado na Universidade Federal do Rio Grande do Sul; Programa de Pós-Graduação em Ciências do Movimento Humano. E-mail: vilodre@gmail.com 
Este texto tem como objetivo apresentar um recorte sobre a formação do Conjunto de Folclore Internacional Os Gaúchos ${ }^{1}$, mais especificamente a sua primeira configuração. Este grupo foi criado em 1959, na cidade de Porto Alegre (RS), e desde então atua com a dança folclórica de projeção, sendo considerado como pioneiro desse gênero no Brasil (CUNHA; FRANCK, 2004).

A dança de projeção baseia-se em manifestações folclóricas ou da cultura popular e, inspiradas por essas manifestações, o(a) coreógrafo(a) ou o grupo que dança realiza um processo coreográfico que contempla algumas adaptações em relação ao tradicional, para que seja apresentado a um público geral. Tais adaptações também são chamadas de estilização, releitura, inspiração folclórica ou adaptação folclórica. Segundo Rocha (2009), esse gênero é uma releitura do folclore que, através de uma pesquisa e mantendo características essenciais da dança folclórica em questão, traz uma maior preocupação artística/estética para a dança. Para Ely (2009), a dança de projeção refina os movimentos, utiliza passos tecnicamente desenvolvidos, organiza e aprimora gestos, arranjo espaçotemporal e temas, a fim de tornar a dança mais atrativa.

Considerando o pioneirismo do Conjunto de Folclore Internacional, buscamos visibilizar sua formação. Para tanto, utilizamos como fundamentação teórica e metodológica a história cultural e a história oral, a fim de produzir fontes, coletar informações e narrar fragmentos de sua história. Além desses campos teóricos, o objeto de pesquisa nos conduziu a aprofundar conhecimentos sobre o desenvolvimento histórico do folclore, por se constituir como o conceito central desta investigação.

Na visão da história cultural, entende-se a história como uma narrativa que não corresponde exatamente à verdade, mas uma versão desta, que se preocupa com o simbólico e suas representações, abrindo o caminho para outras fontes além dos documentos "oficiais" (PESAVENTO, 2005), como fotos, depoimentos orais, troféus etc. Para George Duby, "a História Cultural tem como proposta observar no passado, em meio aos movimentos de conjunto de uma civilização, os mecanismos de produção de objetos culturais" (1982 apud FALCON, 2006, p. 336). Para Pesavento (2005, p. 42), ela teria como proposta "decifrar a realidade do passado por meio das suas representações, tentando chegar àquelas formas discursivas e imagéticas, pelas quais os homens expressaram a si próprios e o mundo".

Na tentativa de narrar a constituição do Conjunto de Folclore Internacional a partir da representação de seus integrantes e do contexto da época, encontramos suporte para a pesquisa nas discussões da história oral, na medida em que ela "permite o registro de testemunhos e o acesso a 'histórias dentro da história' e, dessa forma, amplia as possibilidades de interpretação do passado" (ALBERTI, 2010, p. 155).

As entrevistas deste trabalho integram o conjunto de fontes do Projeto Garimpando Memórias, desenvolvido pela equipe do Centro de Memória do Esporte (CEME), da Escola de Educação Física (ESEF), da Universidade Federal do Rio Grande do Sul (UFRGS) ${ }^{2}$. Os depoimentos tiveram por base os procedimentos descritos no Manual prático para esclarecimento de procedimentos básicos a serem realizados nas entrevistas, do Projeto Garimpando Memórias.

Considerando a natureza desta pesquisa, os nomes dos entrevistados estão explícitos e todos concordaram com sua divulgação. Isso se justifica porque os depoimentos buscam levantar fatos das vidas dessas pessoas, e seus contextos e opiniões são importantes para a construção narrativa aqui

1 Utilizamos durante o texto a expressão conjunto e a sigla CFI para me referir ao Conjunto de Folclore Internacional Os Gaúchos. Passamos, também, a denominar o grupo apenas como Conjunto de Folclore Internacional, pois, como veremos, a expressão Os Gaúchos foi inserida em 1966.

2 Mais informações disponíveis em: <http://www.ufrgs.br/ceme/acervoEntrevistas.php>. Este projeto foi aprovado pelo Comitê de Ética da UFRGS sob o número 2007710. 
proposta. Consideramos ainda que a divulgação dos nomes dos depoentes revela o reconhecimento pelo trabalho realizado e configura um respeito pela produção de tais pessoas. São elas: Nilva Pinto, Antônio Augusto Fagundes, Amélia Maristany Mayer, Carlos Castillo, Claudio Lazzarotto, Nilza Binotto e Marlene Nahas ${ }^{3}$. Os critérios para selecionar esses integrantes do CFI foram a participação nos primeiros cinco anos do grupo e a disponibilidade para conceder entrevista. São os primeiros bailarinos da formação do grupo com permanência até os cinco primeiros anos, sendo que os demais integrantes desse período faleceram ${ }^{4}$ ou não foram localizados.

Algo enriquecedor, principalmente no acréscimo de dados mais detalhados, como datas e locais de apresentações, foi a pesquisa documental. Sendo um conjunto ainda em funcionamento, além dos depoimentos, acessamos três importantes acervos documentais e iconográficos: o do próprio CFI Os Gaúchos ${ }^{5}$, o de sua atual diretora, Nilva Pinto, e da sua figurinista e ex-dançarina Amélia Maristany Mayer. Esse material foi catalogado e sistematizado para compor a narrativa e aprofundar as informações coletadas nas entrevistas e, também, questioná-las.

Para complementar a pesquisa, conferir informações e visualizar o contexto da dança em Porto Alegre no ano de formação do conjunto, recorremos ao acervo de jornais do Museu da Comunicação Hipólito José da Costa ${ }^{6}$. Escolhemos para tal investigação o jornal Correio do Povo, por ser um dos principais jornais em circulação à época e por estar disponível para consulta de forma mais completa.

Uma vez explicitados os caminhos para a produção de fontes desta pesquisa, passamos a descrever como se deu o processo de análise desse corpus empírico, que teve como base a imagem de um quebra-cabeça, proposto por Pesavento, quando indica: “É preciso recolher os traços e registros do passado, mas realizar com eles um trabalho de construção, verdadeiro quebra-cabeças ou puzzle de peças, capazes de produzir sentido" (2005, p. 64). Levando em consideração essa imagem, as informações levantadas nos depoimentos e acervos foram confrontadas e analisadas entre si. Poderíamos pensar aqui que é mais do que um quebra-cabeça linear; são peças que podem fazer relação com diversas outras e nem sempre se encaixam perfeitamente, cabendo um esforço de busca por novos materiais e novos indícios, no caso limitados pela questão de tempo disponível para este trabalho.

\section{A formação inicial do Conjunto de Folclore Internacional}

A primeira proposta para constituição do Conjunto de Folclore Internacional em Porto Alegre foi apresentada durante uma reunião da Mesa Redonda Pan-Americana Feminina - uma associação que realizava encontros entre mulheres da elite, com certa formação no campo cultural erudito. Em Porto Alegre, de acordo com Mayer (2011) e Binotto (2012), essa instituição fazia aproximadamente duas reuniões por mês, e suas participantes eram pintoras, professoras de balé, médicas, advogadas, escritoras, poetisas, a exemplo do que acontecia em várias cidades do continente americano onde havia essa iniciativa. Nas reuniões, discutiam-se temas relacionados a possíveis ações para cultura, educação e arte $^{7}$, tentando integrar pessoas, profissionais ou temáticas de diferentes países,

3 Essas pessoas autorizaram a divulgação da entrevista após a revisão do documento transcrito.

4 Dançarinos que participaram dos primeiros cinco anos, mas já faleceram: Cecília Assenato, Ery Assenato, Jorge

Karam, Juarez da Fonseca.

$5 \quad$ O grupo tem uma sede na Travessa do Carmo, em Porto Alegre, há cerca de 30 anos.

6 Mais informações disponíveis em: <http://www.museudacomunicacao.rs.gov.br/site>.

7 Esse movimento era inspirado nos ideais de paz, união, liberdade e justiça, de acordo com as diretrizes do Libertador da América: Simón Bolívar. Informação disponível em: 
informação esta confirmada nos depoimentos de Amélia e Nilza.

Na cidade de Porto Alegre, tais reuniões provavelmente iniciaram em 1955, quando a organização geral da Mesa Pan-Americana oficializou um convênio com o Rotary Club da cidade (PAN

AMERICAN ROUND TABLE OF EL PASO RECORDS, 2010) sendo que, em uma delas, ocorrida em 1959, foi convidada a participar Marina Cortinas Lampros, uruguaia, pianista, folclorista, professora e estudiosa das danças folclóricas de seu país, que estava morando no Brasil (MAYER, 2011). Nas palavras de Fagundes, "ela tinha muita visão artística de palco e arena" (2011, p. 7).

Marina pretendia fundar um grupo de danças folclóricas para fazer apresentações em programas de televisão, que na época dava seus primeiros passos em Porto Alegre. Essa prática já era comum no Uruguai. O grupo seria mantido por uma emissora e faria coreografias de acordo com a necessidade dos programas televisivos.

As senhoras que participavam da Mesa Redonda Pan-Americana de Porto Alegre indicaram para Marina alguns contatos de pessoas ligadas a escolas de balé e dos Centros de Tradições Gaúchas (CTGs), o que gerou a formação de um grupo, que foi composto mediante algumas negociações.

Segundo o depoimento de Amélia Mayer (2011), a única casada naquele momento, juntamente com seu marido Lauro, ela teve uma conversa com o deputado Porcínio Pinto, para que permitisse a participação de suas filhas Nilva e Nilza, assegurando que o grupo seria formado por pessoas sérias. Nas suas palavras:

Eu tinha 19 anos e fui lá falar com o deputado Porcínio Pinto. Disse a ele que meu marido tinha concordado, pois íamos trazer cultura para as pessoas. Ele concordou, mas perguntou se eu ia fazer parte do grupo. Eu disse: "Sim, eu vou dançar com elas". Ele, então concordou. (MAYER, 2011, p. 7).

Além de Amélia, Nilva e Nilza agregaram-se ao grupo participante do Movimento Tradicionalista Gaúcho, pois uma preocupação de Marina era ter no grupo bons sapateadores, já que um elemento fundamental das danças gaúchas, uruguaias e argentinas era o sapateio. Por essa razão, visitou alguns bailes de CTGs na busca de possíveis bailarinos (MAYER, 2011).

No 35 CTG, encontrou o casal Ery e Cecília Assenato, sendo ele professor de dança gaúcha, oferecendo vários cursos e formando muitos dançarinos. Também foram convidados Juarez da Fonseca e sua esposa Rosa Maria de Bourbon (Rosinha), Jorge Correia Karam e Antônio Augusto Fagundes. Ery, Cecília, Juarez e Rosa provavelmente também frequentavam o CTG Chilena de Prata. Do CTG Pagos da Saudade, da Varig, foi chamado Claudio Lazzarotto ${ }^{8}$, que já era bem conhecido na cidade como sapateador de chula, e seu gaiteiro, Edu Reus ${ }^{9}$, do conjunto vocal Os Carreteiros, que era um grupo vinculado à Radio Gaúcha. Segundo depoimento de Lazzarotto (2012), esses cinco pares teriam feito uma reunião, liderada por Marina e Nilva, e assim fundaram o Conjunto de Folclore Internacional.

Os dançarinos que participaram dessa reunião começaram os ensaios num clube no centro

<http://assessoriainternacional1.blogspot.com/2010/09/mesa-redonda-pan-americana-de-mulheres.html>.

$8 \quad$ Nascido em 1940, em Porto Alegre. Envolveu-se com as tradições gaúchas aos 16 anos. Ajudou a fundar os CTGs Sepé Tiaraju e Pagos da Saudade, da Varig. Foi aluno de dança de Genes Pacheco, professor enviado ao CTG Sepé Tiaraju pelo 35 CTG.

9 Falecido. 
da cidade ao som de Marina ao piano e, em alguns ensaios, a participação de Os Carreteiros, grupo composto por quatro músicos. Nesse momento, Marina também designou quem seriam os pares de dança, considerando a altura, o nível técnico e o entrosamento das pessoas (MAYER, 2011), sendo que os integrantes vindos de CTGs também ensinaram alguns passos de danças gaúchas, especialmente os sapateios (MAYER, 2011; CASTILLO, 2011).

No dia 20 de dezembro de 1959, o grupo fez uma apresentação na inauguração da TV Piratini, a primeira emissora de Porto Alegre, que era ligada à TV Tupi ${ }^{10}$. O repertório da apresentação continha danças gaúchas, com música executada pela professora Marina e pelo grupo Os Carreteiros (PINTO, 2010; FAGUNDES, 2011; LAZZAROTTO, 2012).

Mayer descreve:

Depois disso, eles [a TV Piratini] contratavam de vez em quando para fazer um programa. Mas não era fixo. Eles mandavam uma caminhonete para nos buscar. Aquilo ia até meia noite, e pela madrugada, até que entrasse os programas em determinados horários. Era bastante incômodo. (MAYER, 2011, p. 8).

O ideal de ser um grupo da televisão não foi seguido, e o grupo buscou outros contatos e frentes de divulgação do seu trabalho. Fizeram várias apresentações locais, regionais, nacionais e internacionais.

\section{O contexto cultural que possibilitou a criação de Os Gaúchos}

Apresentados os passos iniciais do CFI, passamos a expor algumas condições de possibilidade que permitiram sua emergência, considerando o contexto histórico da dança folclórica no Rio Grande do Sul.

Nessa direção, merece ser destacada a influência do Movimento Tradicionalista Gaúcho, que teve início entre o fim da década de 1940 e 1950, com o intento de organizar os Centros de Tradições Gaúchas (CTGs) e fortalecer o tradicionalismo (LAYTANO, 1987; CÔRTES, 1994; FAGUNDES, 2005). O objetivo era a afirmação da identidade gaúcha e brasileira, em oposição à alemã, que nesse período estava ligada ao nazismo e à Segunda Guerra Mundial (FAGUNDES, 2005). Foi um primeiro passo, que mostrava o questionamento das identidades estrangeiras, seguido, após o fim da guerra, pela insatisfação da entrada de elementos da cultura norte-americana em Porto Alegre, principalmente pelo cinema (CÔRTES, 1994).

Assim, em abril de 1948, foi fundado o 35 CTG, que buscava resgatar e manter tradições gaúchas tais como poesias, contos e vestimentas, sendo frequentado por profissionais liberais, fazendeiros, intelectuais, poetas, enfim, a elite do estado. A inserção da dança no movimento tradicionalista se deu logo em seguida à sua criação, cuja primeira exibição pública aconteceu no dia 22 de agosto de 1950 durante a III Semana Nacional de Folclore, realizada em Porto Alegre, sob a organização da Comissão Gaúcha de Folclore (CÔRTES; LESSA, 1975). Um incentivador para a disseminação das danças no movimento tradicionalista foi a fundação do Conjunto Folclórico Tropeiros da Tradição ${ }^{11}$, que teve alguns de seus integrantes participando do CFI Os Gaúchos.

10 A TV Tupi foi a primeira emissora de TV do Brasil, trazida por Assis Chateaubriand. A TV Piratini foi fundada pelo Grupo Diários Associados, ligado à TV Tupi.

11 Grupo fundado por Paixão Côrtes, com objetivo de ser um conjunto profissional, que fazia apresentações de danças a partir das pesquisas de Côrtes e Lessa. 
Nesse período o folclore era considerado como uma ciência que estudava a cultura popular. Por essa razão, havia no Rio Grande do Sul um órgão dedicado à divulgação dessa ciência, sob a denominação de Comissão Gaúcha de Folclore, ligada à Secretaria Estadual da Cultura. Criada em 23 de abril de 1948, essa comissão mantinha vínculos com a Comissão Nacional de Folclore ${ }^{12}$, conforme explicitam as matérias publicadas no Jornal do Dia (21/4/1948) e no Diário de Notícias (23/4/1948). O coordenador da comissão, em uma de suas obras, advertia:

É preciso, de qualquer maneira, considerar que os CTGs foram os agentes dinâmicos da restauração de um neorregionalismo. E os folcloristas, de contrapartida, os agentes subjetivos da investigação erudita, classificatória, analisada e do fato fabricado pelo povo. Os dois se completam. (LAYTANO, 1987, p. 144).

Tal anúncio permite entender que tradicionalistas e folcloristas mantinham certa integração, realizando várias ações de divulgação da cultura popular dentro do Movimento Tradicionalista. Nesse período, aconteceram na cidade de Porto Alegre dois eventos nos quais houve o envolvimento da Comissão Gaúcha de Folclore, ambos ligados à Comissão Nacional de Folclore e à Campanha de Defesa do Folclore Brasileiro: a III Semana Nacional do Folclore ${ }^{13}$ (agosto de 1950) e o IV Congresso Nacional de Folclore ${ }^{14}$ (julho de 1959), que contou com a participação dos principais folcloristas do país.

Destacamos essa breve contextualização por entender que há poucos estudos sobre a influência das danças realizadas nos CTGs na história da dança em Porto Alegre, mesmo que sua influência fosse visível no cenário cultural da cidade. Sobre esse tema, ganha destaque o livro Dança: nossos artífices, escrito por Morgada Cunha e Cecy Franck (2004). Ao registrar a história da dança em Porto Alegre desde 1920 até a década de 1980, as autoras citam professores, grupos, bailarinos e técnicos que contribuíram para a consolidação dessa arte. O livro é fruto de uma pesquisa feita a partir de questionários encaminhados àqueles que participaram da dança nesse período e também de dados coletados em jornais da época.

Uma instituição destacada pelas autoras foi a Escola Oficial de Dança do Theatro São Pedro, oficializada em 1943 e dirigida por Lya Bastian Meyer ${ }^{15}$ por cerca de 18 anos. A escola era mantida pelo governo do estado, oferecendo o curso de dança gratuitamente, com a duração de três anos, abordando as danças clássica, moderna e característica. Pelos programas ${ }^{16}$ das apresentações públicas da escola, foi possível perceber o tratamento dessas três linhas, sendo que as danças características ou danças de caráter, como são mais conhecidas, designavam as "danças teatrais originárias do folclore ou das tradições de uma nacionalidade" (FARO; SAMPAIO, 1989, p. 107). As bailarinas que participaram da fundação do Conjunto de Folclore Internacional Os Gaúchos - Nilva, Nilza e Amélia - foram alunas da Escola Oficial e de Lya Bastian Meyer, tendo, portanto, formação nessas três linhas da dança indicadas.

Segundo Cunha e Franck (2004, p. 17), “As décadas de 30, 40, 50 e 60 foram marcadas pela predominância no ensino do ballet, o que consequentemente se refletia nos espetáculos das escolas".

12 Em 1958, com a formação de uma rede de folcloristas espalhadas pelo país, através de comissões estaduais, foi instituída a Campanha de Defesa do Folclore Brasileiro (CDFB) (VILHENA, 1997).

13 As Semanas Nacionais anteriores aconteceram no Rio de Janeiro (1948) e em São Paulo (1949).

14 Os Congressos Nacionais anteriores aconteceram no Rio de Janeiro (1951), em Curitiba (1953) e em Salvador

(1957).

15 Considerada uma das pioneiras da dança em Porto Alegre, junto a Tony Petzhold.

16 Os programas de dança foram pesquisados no Acervo de Dança do CEME e também nos Acervo Pessoal de Nilva Pinto. 
A partir de 1950, os grupos independentes começariam a aparecer. No fim da década de 1950 e na década de 1960, a vida cultural de Porto Alegre, de acordo com dois depoentes (FAGUNDES, 2011; PINTO, 2010), era "fervilhante". O local de maior destaque era o Theatro São Pedro ${ }^{17}$, onde aconteciam apresentações de teatro, música (especialmente orquestras) e dança. "Não existia outro lugar, e era muito fácil conseguir apresentar o espetáculo no maravilhoso teatro" (PINTO, 2010, p. 6). Os grupos e as escolas aproveitavam para realizar suas apresentações nesse local. Antônio Fagundes, em seu depoimento (2011), relata que havia vários grupos de arte no início da década de 1960.

Cunha e Franck (2004) apontam que, além do Conjunto de Folclore Internacional Os Gaúchos, outros seis grupos - dentre os 32 que mencionam na obra - trabalharam com a temática da cultura popular no Rio Grande do Sul. Apesar desse importante registro, conforme outras fontes pesquisadas, é possível notar a existência, mais especificamente a partir de 1949, de outros grupos de dança ligados ao Movimento Tradicionalista e que, mesmo fazendo parte da história da dança na cidade, não são lembrados nas obras referenciais.

Em sua constituição, o CFI teve influência dessas quatro tendências apresentadas: movimento tradicionalista, modernização da arte, folclore e dança cênica. Essas influências são percebidas na sua temática de trabalho (inicialmente focando nas danças folclóricas da América Latina) e no estilo do grupo (folclore de projeção, ou folclore "moderno", e a dança cênica).

\section{A visibilidade mediante os apoios culturais e políticos}

A formação do CFI foi possível, ainda, pelo pertencimento social de seus integrantes, em sua maioria, provenientes de famílias das elites políticas e culturais do Rio Grande do Sul. Tal condição possibilitava que em algumas viagens fossem os próprios integrantes do grupo que financiassem os espetáculos e a realização de turnês. Segundo Nilza Binotto:

As minhas primeiras viagens que fiz foi com o Conjunto. Tudo por nossa conta. Não a viagem em si, mas a comida, e outras coisas. A gente levava um dinheirinho. E no Uruguai, a vez que a Dona Marina nos levou, foi a primeira viagem, tinha uns que não tinham dinheiro, daí a Nilva e eu fomos jogar no cassino e ganhamos dinheiro, a gente dava comida para os outros [risos]. Nós já passamos por tudo. Tinha dois ou três guris que não tinham dinheiro. E aí nós ajudávamos, um ajudava o outro. (2012, p. 11).

Sobre apoios externos, Lazzarotto diz:

Nunca, nada. Nem apoio político, nem financeiro de ninguém. Não recebíamos nada de ninguém. Cada um custeava sua passagem de ônibus para ir para os ensaios, pois naquela época ninguém tinha recurso. Cada um arrumava sua bombacha, suas botas, cada um se virava do jeito que desse, porque não existia apoio não. (2012, p. 7).

Durante os anos iniciais do grupo, identificamos alguns apoios institucionais, políticos e culturais, como do governo do estado para a viagem de avião até Buenos Aires, para o Certame PanAmericano de Danças Folclóricas; da Varig; da Caravana de Cultura - pelo Ministério de Educação e Cultura; do governo brasileiro, para apresentações em Brasília, algumas vezes no avião da Força

17 Fundado em 1858 e administrado pelo estado, este é um tradicional teatro localizado na Praça Marechal Deodoro, centro de Porto Alegre (RS). 
Aérea. Esses apoios também revertiam em propaganda para os financiadores, como narra Carlos Castillo em sua entrevista:

[...] quando a Varig iniciou suas linhas internacionais, o marketing dela era levar o nosso grupo para fazer shows. Então nós andamos por este mundo todo fazendo shows para a Varig. Metade era dos Gaúchos, metade não, era outro grupo, mas gente muito legal (2011, p. 6).

Em relação à política, durante o período analisado, o Rio Grande do Sul contou com os governos de Ildo Meneghetti (de 1955 a 1959 e de 1963 a 1966) e Leonel Brizola (de 1959 a 1963); o primeiro do Partido Social Democrático (PSD) e o segundo do Partido Trabalhista Brasileiro (PTB). Ambos figuram na trajetória do Conjunto de Folclore Internacional Os Gaúchos. Nilva comentou que o governador Brizola convidava o grupo para dançar em cerimônias oficiais, principalmente no Palácio Piratini, por ocasião de inaugurações e comemorações do governo.

O deputado Porcínio Pinto, pai de Nilva e Nilza, também era do PSD nesse período e teve influência em pelo menos três momentos importantes, segundo os depoimentos de Antônio Fagundes, Amélia Mayer e Carlos Castillo: ao agradecer o apoio para o grupo comparecer ao Certame Pan-Americano de Danças Folclóricas, na articulação para se conseguir que o CFI fosse reconhecido como de utilidade pública e na dispensa quando necessário de algum funcionário público que dançava no grupo. Vejamos:

Falamos também com o pai da Nilva, o deputado Porcínio Pinto para ver algo, no estado. Ele nos ajudou, mas nunca recebemos nada por isso. Era apenas um reconhecimento, ficou registrado como sendo um trabalho cultural no qual divulgávamos as danças de toda a América aqui. (MAYER, 2011, p. 9).

Não dá para dizer que teve, mas também não dá para dizer que não teve [apoio]. Porque o pai da Nilva e da Ziza era deputado, Porcínio Pinto, muito ligado ao governador do estado Ildo Meneghetti. Então ele nos conseguia facilidades de viagem, se precisava dispensar um bailarino que era funcionário público, como eu, ele tratava uma licença, uma dispensa e conseguia que o funcionário viajasse. Nós tivemos cobertura do deputado Porcínio Pinto, muitas vezes nos ajudando nesses pequenos entraves burocráticos. (FAGUNDES, 2011, p. 11).

Na década de 1960, o conjunto recebeu também o apoio institucional da Secretaria de Turismo do Rio Grande do Sul, que tinha um projeto para levar apresentações artísticas em cidades do interior do estado e incluía o CFI entre os grupos, realizando apresentações nos fins de semana (PINTO, 2010). A secretaria pagava pelo transporte, pela alimentação e, quando necessário, pela hospedagem.

Também a seção de cultura da prefeitura apoiou o CFI entre os anos de 1960 e 1963. Nos acervos pesquisados, identificamos 21 reportagens que mencionam esse apoio, referentes a 15 apresentações na cidade de Porto Alegre.

O CFI também contou com o apoio cultural de autoridades da área, como Paixão Côrtes, Barbosa Lessa, Lauro Rodrigues e Renato Almeida. A atuação de Lauro Rodrigues foi fundamental para a primeira viagem do conjunto à nova capital federal, assim como a contribuição de Renato Almeida (coordenador da Comissão Nacional de Folclore), que acatou a indicação do conjunto para representar o Brasil no Certame Pan-Americano de Danças Folclóricas, em Buenos Aires. Por serem autoridades quando se tratava de folclore, a indicação e o reconhecimento dessas pessoas traziam 
prestígio e agregavam valor ao grupo.

Por meio dos depoimentos e também de uma reportagem, percebemos que, para além de todos os apoios, o espírito de família reinava no grupo. Era um ambiente harmonioso e de camaradagem. "Era um pessoal muito unido, muito amigo, um pessoal muito unido. Nunca teve uma briga entre nós" (FAGUNDES, 2011, p. 12). Mayer (2011) diz também que a troca de experiências entre os rapazes do CTG e as moças do balé foi muito proveitosa, e os integrantes continuaram amigos. Castillo afirma: "Nós formamos um grupo que era mais que um grupo, era uma família. Todos muito amigos, muito unidos" (2011, p. 5). Talvez por isso não tenha havido tanta renovação no grupo nesse período e era possível o investimento pessoal, já que eles não sentiam aquilo apenas como um trabalho, mas como uma família. Todavia, os apoios (político, financeiro e cultural) ajudaram a sustentação da estrutura e, especialmente, possibilitaram as viagens e a divulgação nacional e internacional do conjunto.

\section{Considerações finais}

A primeira formação do CFI foi marcada por alguns fatores do contexto cultural de Porto Alegre, com destaque para a forte presença na cidade dos CTGs e das escolas de dança; a realização da Mesa Pan-Americana Feminina, que já planejava ações de integração da cultura americana; a inauguração da emissora de televisão local; e a aceitação e disponibilidade de pessoas para integrar o conjunto.

Os primeiros dançarinos eram originários de CTGs e da Escola de Dança de Lya Bastian Meyer, pessoas já envolvidas com a dança e que, em sua maioria, possuíam boa condição financeira. As adaptações foram o grande diferencial do conjunto. Os elementos utilizados para esse fim abrangiam tanto aqueles vindos do balé como outros, por exemplo, adaptações no figurino e na música. As estampas eram arranjadas para se formar um show, um espetáculo que trazia as danças e alguns elementos (músicas, poesias e versos) que ligavam o quadro coreográfico à identidade nacional apresentada.

Além do reconhecimento pelo seu estilo, que para a época era inovador, o CFI contou com diversos apoios que permitiram sua estruturação e estabilidade. Os apoios culturais e políticos tiveram mais destaque e possibilitaram: o maior alcance do conjunto pelos convites para apresentações; a conquista do título de instituição de utilidade pública; a cobertura de algumas despesas em viagens; a liberação de alguns espaços para as apresentações. Porém, o apoio financeiro aos dançarinos e para despesas cotidianas do grupo não foi verificado pelas fontes analisadas.

Destacamos também que o Conjunto de Folclore Internacional Os Gaúchos teve e ainda tem importância no cenário da dança em Porto Alegre. São incontáveis as apresentações nesses mais de 50 anos de existência. Suas performances têm colaborado para a divulgação das danças folclóricas e para o enriquecimento cultural da cidade. Consideramos como principal conquista a inserção do folclore, por vezes menosprezado, no cenário da arte reconhecida e valorizada.

\section{Referências}

ALBERTI, Verena. Histórias dentro da História. In: PINSKY, Carla Bassanezi (Org.). Fontes históricas. 2. ed. São Paulo:Contexto, 2010. p. 155-202. 
BINOTTO, Nilza Maria Pinto. Depoimento de Nilza Maria Pinto Binotto: Projeto Garimpando Memórias. Porto Alegre: Centro de Memória do Esporte - Esef/UFRGS, 2012.

CASTILLO, Carlos Pereira. Depoimento de Carlos Pereira Castillo: Projeto Garimpando Memórias. Porto Alegre: Centro de Memória do Esporte - Esef/UFRGS, 2011.

CÔRTES, João Carlos D'Ávila Paixão; LESSA, Barbosa. Danças e andanças da tradição gaúcha. Porto Alegre: Garatuja, 1975.

CÔRTES, João Carlos D’ Ávila Paixão. Origem da Semana Farroupilha e primórdios do Movimento Tradicionalista. Porto Alegre: EVANGRAF, 1994.

CUNHA, Morgada; FRANCK, Cecy. Dança: nossos artífices. Porto Alegre: Movimento, 2004.

ELY, Vitor Hasen. Motivos que levam jovens adultos, de ambos os sexos, a frequentarem e permanecerem em grupos de danças folclóricas de projeção não remunerados em Porto Alegre. 2009. 52 f. Monografia (Conclusão de Curso) - Escola de Educação Física, Universidade Federal do Rio Grande do Sul, Porto Alegre, 2009.

FAGUNDES, Antônio Augusto. Depoimento de Antônio Augusto Fagundes: Projeto Garimpando Memórias. Porto Alegre: Centro de Memória do Esporte - Esef/UFRGS, 2011.

FAGUNDES, Antônio Augusto. Tradicionalismo. Caderno de História, Porto Alegre, n. 22, 2005. Disponível em: <http://www.memorial.rs.gov.br/cadernos/tradicionalismo.pdf $>$. Acesso em: 2 jun. 2012.

FALCON, Francisco José Calazans. História cultural e história da educação. Revista Brasileira de Educação, v. 11, n. 32, p. 328-375, maio/ago. 2006.

FARO, Antônio José; SAMPAIO, Luiz Paulo. Dicionário de Balé e Dança. Rio de Janeiro: Zahar, 1989.

LAYTANO, Dante de. Folclore do Rio Grande do Sul: levantamento dos costumes e tradições gaúchas. 2. ed. Caxias do Sul: EDUCS, Porto Alegre: Escola Superior de Teologia São Lourenço de Brindes, Nova Dimensão, 1987.

LAZZAROTTO, Claudio Antônio Guerra. Depoimento de Claudio Lazzarotto: Projeto Garimpando Memórias. Porto Alegre: Centro de Memória do Esporte - Esef/UFRGS, 2012.

MAYER, Amélia Maristany. Depoimento de Amélia Maristany Mayer: Projeto Garimpando Memórias. Porto Alegre: Centro de Memória do Esporte - Esef/UFRGS, 2011.

PAN AMERICAN ROUND TABLE OF EL PASO RECORDS. 1921 - 2010, MS 526. C.L. Sonnichsen Special Collections Department. The University of Texas at El Paso Library, 2010. Disponível em: <http://www.alianzamrp.org/esp.html>. Acesso em: 22 mar. 2012.

PESAVENTO, Sandra Jatahy. História \& história cultural. 2. ed. Belo Horizonte: Autêntica, 2005.

PINTO, Nilva Terezinha Dutra. Depoimento de Nilva Terezinha Dutra Pinto 1: Projeto Garimpando Memórias. Porto Alegre: Centro de Memória do Esporte - Esef/UFRGS, 2010.

ROCHA, Gilmar. Cultura popular: do folclore ao patrimônio. Mediações - Revista de Ciências Sociais, v. 14, n. 1, p. 218-236, jan./jun. 2009. Disponível em: <http://www.uel.br/revistas/uel/index.php/ mediacoes/article/view/3358>. Acesso em: 13 maio 2012. 
Cena 15

Christiane Garcia Macedo e Silvana Vilodre Goellner

VILHENA, Luís Rodolfo. Projeto e missão: o movimento folclórico brasileiro (1947-1964). Rio de Janeiro: Funarte; Fundação Getúlio Vargas, 1997. 